\title{
A CONTRIBUTION TO CONSIDERATIONS ON THE PHENOMENON OF PEDOPHILIA IN THE CONTEXT OF CHILD SAFETY
}

\author{
Dorota Kamuda ${ }^{1}$, Oktawia Jurgilewicz ${ }^{2}$, Lukasz Świerczewski ${ }^{3}$ \\ 1,2Rzeszów University of Technology, Aleja Powstańców Warszawy 12, 35-959 Rzeszów, Poland \\ ${ }^{3}$ University of Natural Sciences and Humanities in Siedlce, Stanistawa Konarskiego 2, 08-110 Siedlce, Poland

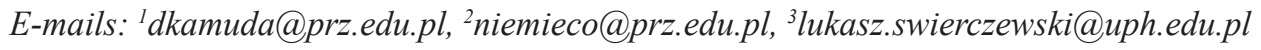

Received 15 October 2021; accepted 14 October 2021; published 30 October 2021

\begin{abstract}
In the present age, the phenomenon of pedophilia is a very important and as dangerous social issue, characterised by a complex and heterogeneous nature. It is an outcome of various factors inherent in the social, psychological, biological and cultural background, which constitute a homogeneous and coherent whole. Pedophilia polarizes social attitudes and leads to heated discussions. In the current reality, sexualisation of the child's person is visible in the media, which can contribute to the unconscious perception of the child in terms of a sexual object. An important issue from the point of view of sociological considerations is to be able to answer questions about the etiology and symptomatology of the phenomenon.
\end{abstract}

Keywords: criminology; the phenomenon of pedophilia; child safety; security

Reference to this paper should be made as follows: Kamuda, D., Jurgilewicz, O., Świerczewski, Ł. 2021. A contribution to consideration on the phenomenon of pedophilia in the context of child safety. Journal of Security and Sustainability Issues, 11, 517-523. https://doi.org/10.47459/jssi.2021.11.47

JEL Classifications: K14

Additional disciplines: law

\section{Introduction - the concept and etiology of pedophilia.}

In criminological and legal literature, the notion of pedophilia is presented in a heterogeneous way, which, among others, makes it difficult to identify the phenomenon appropriately and effectively fight it. In order to capture the essence of this concept in a broad sense, it should be said that this is a phenomenon that comes down to the sexual activity of an adult with a child. According to Z. Lew-Starowicz, pedophilia is "a common paraphilia that involves achieving sexual satisfaction by dealing with children” (Lew-Starowicz, 2000).

According to K. Imieliński, pedophilia is "a sexual aberrance manifested in a tendency to engage in sexual practices with children" (Imieliński, 1990). In turn, B. Hołyst claims that pedophilia is "a sexual deviation manifested in a tendency to engage in sexual practices with children" (Hołyst, 2007). Whereas, according to the World Health Organization, pedophilia is considered to be "sexual violence against children, which means abusing a child for sexual pleasure by adults and older individuals" (Lew-Starowicz, 1992).

In legal aspect, the essence of pedophilia is a prohibited act, consisting in sexual intercourse or in undertaking other sexual activities by an adult with a minor under 15 years of age. The determinants of the phenomenon of pedophilia should be traced to biopsychological and social background. In the biological approach, the phenomenon of pedophilia is explained by biological mechanisms that constitute a certain element independent of 
human being and formulated in the prenatal and postnatal period, as well as in the course of human life, in the subsequent stages. In the opinion of numerous researchers, this independent element is associated with disorders in the functioning of the endocrine glands, the function and structure of the central nervous system, and with chromosomal impairments (Beisert, 2012).

According to endocrine theory, the activity of an adult male, including sexual activity, depends on the work of androgens. The essence of the problem boils down to impaired secretion of hormones into the blood, which cause the destabilisation of the emotional sphere, which in turn, translates into aggressive behaviour, including the intensity of sexual drive. It is assumed that increased level of androgens will let ignore the prohibition of adult sexual intercourse with a child. An alternative position in explaining the determinants of pedophilia is the impact of chromosomal impairment on human behaviour. It assumes that changes in the quantity and quality of autosomes lead to impairments in the development of the emotional, intellectual, physical and social spheres. In the case of males, it is about the abnormal karyotype (47XYY), i.e. additional chromosome inherited from the father and marked with the $Y$ symbol. This situation causes some serious impairments in the emotional sphere leading to aggressive behaviour (Hołyst, 2016).

From psychological viewpoint, the major factors contributing to pedophile tendencies are personality traits, relationships, mechanisms of affect regulation and social competences. Significant impairments may occur during three stages of human development, i.e.: early phase (natural autism and natural symbiosis), narcissistic phase (differentiation and integration) and Oedipal phase (pre-school period). Symbiotic phase disorders have an impact, which boils down to too long (close) or too short relationship of son with the mother. Object relationship theory is a part of a group of subjective theories that emphasize the role of developmental disorders in the genesis of sexual deviations. In turn, social learning theories also highlight the correlations of the perpetrator with disturbed course of development in the formation of sexual deviations. They explain sexual behaviour as an outcome of the learning process. They focus their thoughts on the processes that have a fundamental impact on the learning process of deviant sexual behaviour, such as: vicarious learning, participant modeling and symbolic modeling. Vicarious learning occurs when a child acts as an observer of another child's sexual abuse or when the content relating to sexual abuse of other children is presented to the child. Participant learning refers to a situation in which a person abused during childhood upon reaching maturity becomes a sexual perpetrator as a result of previously acquired experience. Symbolic learning points to the role of masturbation phantasies in the process of learning sexually deviant behaviours. Depending on a given social model, the dominant view is that the environment in which a given person acts is a stimulant of all kinds of sexual deviations and is responsible for their preservation. Hence, the social model emphasises that the main factor causing pedophilia is a specific social system (Pastwa-Wojciechowska, 2013).

\section{Typology of pedophilia}

There is a number of different typologies of pedophilia in the existing literature on the subject. The most frequently quoted types include the typology according to S. Freud, A.N. Groth, C.N. Hall as well as R. Hirschmann and W. Glasser. S. Freud has singled out two types of perpetrators. The first type depicts the perpetrator (male) for whom girl becomes the object of a mature woman, whereas he also maintains relations with adult women and his tastes depend on current availability of a given person. The second type characterises the perpetrator who is interested exclusively in a child as the one and only object of his special sexual attention. A. N. Groth has discerned two type of perpetrators - fixated and regressive pedophiles. Fixated perpetrator is presented as a person for whom child is the object of sexual desire in terms of attractiveness, and there is no predisposition to chemical and non-chemical addictions. His behaviour is controlled and subject to a specific plan of conduct, he likes the company of children, and has an infantile personality. In the vast majority of cases, such perpetrator is a loner, who most often likes boys, who subsequently become harmed by his actions. In turn, regressive perpetrator is a person who has had sexual contact with mature women, and who engages in sexual practices with children in situations of severe stress. However, these situations are rare and in most cases they tend to occur when perpetrator is in the state of intoxication. C.N. Hall and R. Hirschman have discerned the following perpetrators of pedophilia: classical, incestuous, situational and preferential. Classical perpetrators are people who 
experience strong sexual stimuli in relation to children, having numerous sexual experiences with children. Incestuous pedophiles tend to misjudge child's attitudes, they have the ability to plan and regulate emotions. In turn, situational perpetrators are prone to experiencing negative emotional states that cause impulsiveness, loss of control over the sphere of their own behaviour and planning of their actions. In contrast, preferential pedophiles have serious difficulties in establishing and maintaining mature intimate partnerships (Pieszko, 2012).

While presenting the typology of pedophiles, W. Glasser took into account their emotional attitude towards abused child, while in the process discerning uncomplicated and pseudoneurotic types. Uncomplicated pedophiles are deprived of empathy and feelings, while pseudoneurotic pedophiles tend to be people of great kindness and tenderness. Glasser assumes that pedophilia is based on two elementary mental processes. First of all, pedophile treats himself as a child and does not accept that there are differences existing between him and the child (he does not accept the fact that his psychophysical structure determines other needs and behaviours). He is convinced that experiencing sexual intercourse that gives him full satisfaction is also in line with child's expectations. Secondly, any predisposition to abusing children is rooted in aggression (Pospiszyl, 2009).

\section{Typology of pedophilia victims}

In victimological literature, victims of sexual abuse are most often divided into random and participating. The first group concerns children sexually abused by strangers and these are usually once-off situations. The second group pools children who experience sexual harm from their relatives (family and friends) and these are situations that sometimes last for years. Some publications draw attention to typology that discerns participating, hidden, provocative and false victims. Children due to their credulity brought about by the lack of relevant knowledge and life experience and in some cases due to their loneliness, can easily be cheated and manipulated, and thus become victims of pedophiles (Kopiński et al, 2006).

The factors of increased risk of becoming a victim of pedophilia include: the breakup of family bonds, adoption, conflicts and misunderstandings in the family, the use of physical violence in contacts with children, interest in sex on the part of children, impaired personality, social isolation of the family, and disability. In case of adolescent girls, the factors would also include the absence of emotional ties with mother, disturbed personality of the mother, lack of father, loneliness caused by a lack of friends and no friendship, as well as mass culture and pedophile pornography. Boys are much less likely to become victims of incestuous relations, while much more often they are abused by so-called "False uncles", colleagues of father, mother, teachers, trainers, priests or by accidentally met men, e.g. people hanging around children's gatherings (Lew-Starowicz, 1992).

\section{Phenomenology of the phenomenon}

Sexual abuse of children is a fairly widespread phenomenon. It usually takes place where access is made difficult for outside observers, between close relatives or in relations that hypothetically should ensure the safety of child. This condition leads to a situation in which it is difficult to protect people from harm. The situation becomes particularly difficult when the perpetrator is a person who occupies an important place in child's life, someone arousing child's deepest feelings. As a result, the child's mental sphere permeates fear of losing love of the adult figure, pain, sense of guilt for the situation, a sense of loneliness and rejection, as well as fear of the future. In addition, it is most common that blackmail is used by the perpetrator to prevent from disclosing the facts of sexual abuse. Such situation is most common in the so-called "families with a secret." In such context, keeping such a family together and alienating it from the environment and from other people becomes the unconscious, overriding goal. Symptomatic of such situations are most often cases when father treats his daughter as a partner, when he seduces her and behaves towards her like as if she was an adult woman. In turn, the mother generally demonstrates a passive attitude and sometimes blames her daughter for the whole situation. In the case of perpetrators from outside the circle of close relatives, children are most often exposed to assault in places where they stay in large groups, being left without the supervision of adults (parents, guardians), e.g. on playgrounds, in supermarkets, amusement parks, etc. There is a group of perpetrators of pedophilia, whose work routine coincides with frequent contact with children, such as boarding school educators, teachers, social 
activists in community centres, sports clubs, and priests. These people are characterised by the ability to "be a child", which means that they are likely to gain child's trust rather quickly. Child's sexual abuse may also apply to older pedophile men who provide care or financial support for sex services. The basic group of perpetrators of pedophile acts are people whose goal is to look at (to see) a naked child's body, and when greater sexual arousal is present - to caress, and insert hands or a finger into the genitals (Choromańska, Mocarska, 2009).

In a significant number of incestuous and pedophilic behaviours, these actions are assessed by the child as appropriate reactions of showing love. Child believes his guardians without any reservations, because the child loves them immensely, which makes them fulfill their whims (wishes) without any inhibitions. The following elements that are part of incestuous behaviour can be distinguished:

- seduction - activities aimed at activating the child's emotional involvement and at making the child dependent on the adult emotionally, erotic behaviours are most often presented in the form of play;

- sexual activities - come down to touching the child through clothing, caressing, watching them, watching masturbation, and ultimately, to engaging in sexual intercourse;

- secret - behaviours consisting in concealing the fact of harassment, most often to prevent legal consequences, environmental stigma, blackmail, fear of loss of life and health, it also involves compensation from the perpetrator in the form of money, toys, etc.;

- disclosure - the act of making the fact of sexual harassment public, most often by outside people;

- suppression - behaviour related to a situation in which perpetrator emphatically denies his act, and when he presents his victim as an unreliable, lying, untrustworthy person, which actually makes the child become snappish, arrogant, underachieving, truant, often fleeing from the home, etc. (Wiadera-Wysoczańska, 1988).

Some other signs indicating that child has been abused may include regression, crying (fear) when being touched or hugged by an adult, feeling lonely, rejecting contact with other children, bedwetting (fear), bruises or other kind of damage to skin, fear of undressing to sleep, abdominal pains, somatic pains, etc. Children may also demonstrate attitudes and behaviours, which are uncanny to others, such as touching own genitals and genitals of other people, discussing sexuality topics without any particular reason, engaging in acts of sexual violence directed at toys. According to D. and P. Mrozek, there are four types of signs of sexual abuse: showing genitals, presenting sexual activities and providing pornography to children; petting with minors and violation of intimate parts during these activities, inter alia, touching various erogenous spheres of a child in order to initiate sexual intercourse, i.e. raping a child (Mrozek, 1985).

While analysing specific views and concepts regarding the subject in question, which have been coined by A.P. Spencer, one can observe a kind of regularity in the behaviour of most sex offenders, manifested in a type of criminal cycle, which consists of:

- Stage I (normality) - perpetrator behaves normally, while manifesting some intermittent elements of impairment;

- Stage II (accumulation of negative feelings) - the victim presents a depressed attitude, helplessness, inability to overcome this state with active rational behaviour;

- Stage III (phantasies) - the perpetrator tries to make his potential victims utterly dependent on himself, he demands total love and submission, and as a consequence of this, unconditional sexual submission;

- Stage IV (criminal thinking) - on the one hand, the perpetrator is looking for some sort of justification for his offense, while on the other, he is working out the most effective and camouflaged method of satisfying his own sexual desire;

- Stage V (trigger reaction) - it constitutes a psychological transition from the sphere of motivation to criminal behaviour (it is a part of vicious circle of compulsive behaviours);

- Stage VI (recurrence of persistent phantasies) - the perpetrator's behavior is focused at fulfilment of various phantasies related to the sexual sphere;

- Stage VII (finding the victim) - while phantasising, the perpetrator seeks out a specific corporeal object that causes an irrepressible desire to meet his sexual needs;

- Stage VIII (working on the victim) - the perpetrator, using observation, gathers accurate information about his victim, e.g. her preferences, lifestyle, addictions, etc., 
- Stage IX (fulfilment) - the perpetrator implements his plan aimed at meeting his sexual needs, e.g. by using violence against the victim;

- Stage X (phantasy reinforcement) - as a result of previous experience in dealing with the victim, through phantasies, the perpetrator obtains additional reinforcement of his sensations from criminal behaviour;

- Stage XI (feeling guilty and fear of disclosure) - the perpetrator uses the so-called camouflage of his activities, e.g. he is trying to forge a situation that would present him as a victim of sexual abuse;

- Stage XII (attempt to mend the wrongs) - through his actions, the perpetrator tries to influence the victim not to disclose the fact of sexual abuse, e.g. he intimidates the victim, offers her money, apologises to her;

- Stage XIII (disappearance of guilt) - the perpetrator reassures himself that he can abuse the victim again (Pastwa-Wojciechowska).

The intensification of the phenomenon of pedophilia should be explained by the fact of the growing popularity of social liberalism, which is increasingly contributing to the primitivisation and impairment of the personality sphere of many people. An emphatic example of this may be seen in the establishment and functioning of organisations that associate pedophiles, which in certain countries operate either completely legally, and in others, semi-legally or undercover. They use methods to fight for their rights, by reverting to national minorities functioning in a given country. They are trying to argue that pedophilia should be legalised as a normal social phenomenon, and above all, that relationships with children over a certain age should be allowed by the law. As arguments for their demands, they refer to the issue of tolerance of development, i.e. that the modern youth become mature earlier and that there is a greater understanding of law enforcement and justice representatives for the attainment of children's sexual preferences. All the more so that the "myth of child innocence" is a concept of people who do not know the child's psyche and who are suffering from trauma and sexual inhibitions. A blatant example of the struggle for pedophile rights was the action of the Pastor J. Douce (clergyman of the Baptist Church), who claimed that there should be tolerance and understanding of pedophilia in social life. From the social point of view, the phenomenon of the existence of different relations and criminal groups focused on the production and distribution of child pornography and human trafficking is very worrying. It should be emphasised that the Internet plays a huge role in this respect, as it greatly facilitates in establishing contacts between people involved in the distribution and trade of pornographic material.

\section{Conclusion}

Pedophilia is a phenomenon that has existed since the earliest times and is subject to legal regulations inextricably linked to the development and organisation of the social life. Depending on a given social culture, sexual abuse of children can be more or less covert, it can grow in its intensity or recede, be tolerated (accepted) or severely punished. The uptrends in the phenomenon of pedophilia should be linked with the rising popularity of liberalism in the social sphere of life, which brings with it several social benefits, but also a lot of hazards. One of these hazards is pedophilia. The determinants of pedophilia are diverse and complex. It is a combination of factors inherent in the biopsychological sphere as well as specific in a given social structure and in specific situations. The methods of action adopted by pedophilia perpetrators are also diverse. The interaction of the perpetrator of pedophilia with his victim, as well as the methods of the former aimed at bringing about the sexual abuse of another person are not always the same. This situation also draws our attention to problems concerning the assessment of the invasiveness of the act. For a given person affected by the act of the perpetrator, the outcomes are always negative, but are specific for each individual. Persons affected by sexual paraphilias constitute a very complicated set in both diagnostic and therapeutic aspects. The most common problems that are encountered here include:

- rigidity and longevity of particular forms of behaviour,

- the vast majority do not perceive their perversion as disturbed behaviour,

- their treatment is brought about by coercion, most often as a result of a court judgment,

- they are characterised by substantial manipulative skills, which has a significant impact on the effects of treatment,

- negative impact of this group on the functioning of psychotherapists. 
Considering the above-mentioned determinants, the therapy of pedophilia perpetrators is one of the most difficult. The model of clinical interaction includes therapeutic work with convicts, both, during and after the term of their imprisonment. Apart from therapeutic interactions, a very important role in the effective prevention of pedophilia is played by law enforcement, justice, public administration, non-governmental organisations and by the society as a whole. To recapitulate, it should be stated that only measures based on continuity, regularity and complementarity can ensure enhanced treatment effectiveness and can minimise the risk of pedophile behavior recurrence. Taking into account the intensity, scale and profound nature of the disorder, the appropriate measures taken should be well adjusted, i.e. all the way from therapy, through education, control, coordination to specialist intervention. To this end, an effective control and prevention system should be developed and implemented (Pastwa-Wojciechowska, 2012).

\section{Possible ways of countering the phenomenon}

For many years, work has been done on coming up with more and more effective and efficient methods of preventing and combating pedophilia and sexual crime in a broad sense. These measures are aimed at developing a system that would be multidirectional, coordinated and systematic, based not only on law enforcement and judicial authorities, but also on the actions of state administration bodies and on the participation of broad social circles. In this respect, four most significant preventive strategies can be referred to. The first one directly addresses measures to prevent and combat pedophilia and other sexual offenses that are implemented by law enforcement agencies. Effective prosecution of perpetrators of pedophilia and of other sexual crimes, effective identification of the potentially criminal environment and its proper monitoring is also a part of preventive actions. The second one concerns the action taken by the judiciary system in the field of prevention by applying appropriate preventive measures, e.g. detention on remand, and in particular, appropriate treatment of the harmed party (victim) during a court hearing. Yet another strategy of preventive interventions should be focused around social entities that would more effectively eliminate harsh material and living conditions of families and that would expand the scope of sexual education of young people with particular emphasis placed on pedophilia. The fourth preventive strategy concerns the organisation of local government administration, which should step up its activity in the field of reducing alcohol consumption, raising the level of culture and in organising tourism and leisure activities so as to encompass the needs of the society overall. Effective prevention of pedophilia and of sexual crime understood in a broad sense requires extensive action of the community as a whole. As B. Hołyst states, "proper activation of the entire society, both, focused on direct measures, and on the projects to improve the functioning of specific social institutions, which is obviously a long-term process, can bring effective results in fighting sexual crime. The activation of the whole society should be understood as the dissemination and practical application of the right model of behaviour of potential victims of crime". Since the beginning of the 1980s, the society, and in particular, its representative - the media, have demonstrated unprecedented on such a scale interest in the issue of pedophilia. Television covers cases regarding sexual harassment of children. In the media, more and more frequently appears information that warns against criminals - sex offenders, and in particular, pedophiles. Despite these measures, the situation in the fight against pedophilia is still very challenging and it does not produce the right effects. To recapitulate, it should be stated, that there is a need to develop the right prevention strategy and prevention measures to address the issue of pedophilia. Only an approach based on complexity, regularity and continuity of impact can enhance the effectiveness of measures aimed at preventing pedophilia. The authors agree with Hołyst (2016), that the gradation and hierarchy of applied measures should also be adjusted depending on the scope and intensity of the impairment of sexual sphere; covering such possible solutions, as therapy, education, monitoring and control, as well as specialist intervention.

\section{References:}

Abraham, S. (2001). Chechnya: Between War and Peace. Human Rights Brief, 8(2).

Amnesty International (2000). Lawlessness, violence, impunity. The Russian Federation and the Republic of Chechnya in documents (Bezprawie, przemoc, bezkarność. Federacja Rosyjska wraz z Republika Czeczenii w dokumentach), Warszawa. 
Borucki, M. (1999). Universal history until 1998 (Historia powszechna do 1998 roku), Warszawa.

Beisert, M. (2012). (Pedophilia - the origin and mechanism of the disorder) Pedofilia-geneza i mechanizm zaburzenia, Sopot.

Choromańska, A., Mocarska, D. (2009), Sexual deviation and crimes - qualification, legal aspects (Dewiacje i przestępstwa seksualnekwalifikacja, aspekty prawne), Szczytno.

Hołyst, B. (2007). Forensic sociology Socjologia kryminalistyczna, Tom 1, Warszawa.

Hołyst, B. (2016). Criminology, Kryminologia, Warszawa.

Hołyst, B. (2018). Forensics Kryminalistyka, Warszawa.

Imieliński, K. (1990). Sexiatry (Seksiatria), t.1, Warszawa.

Kopiński, M., Kącki, M. (2006). Boylover is an attempt to soften pedophilia (Boylover to próba zmiękczania pedofilii). Gazeta Wyborcza.

Lew - Starowicz, Z. (2000). Forensic sexology (Seksuologia sądowa), Warszawa.

Lew - Starowicz, Z. (1992). Sexual violence (Przemoc seksualna), Warszawa.

Mrozek, D., Mrozek, P. (1985). Child maltreatment, Oxford: Blackwell.

Pastwa-Wojciechowska, B. (2013). Psychopaths - perpetrators of sexual crimes (Psychopaci - sprawcy przestepstw seksualnych), Gdańsk.

Pieszko, J. (2012). Pedophilia-violence against children (Pedofilia-przemoc wobec dzieci), Kraków.

Pospiszyl, K. (2009). Sexual offenses Przestęstwa seksualne, Warszawa.

Dr. Dorota KAMUDA, Rzeszów University of Technology, PL. Research interests: internal security, criminal law. ORCID ID: 0000-0002-4415-527X

Dr. Oktawia JURGILEWICZ, Rzeszów University of Technology, PL. Research interests: internal security, environmental protection, criminal law.

ORCID ID: 0000-0003-1293-6933

Dr. Lukasz ŚWIERCZEWSKI University of Natural Sciences and Humanities in Siedlce, PL. Research interests: internal security. ORCID ID: 0000-0002-8258-6388

This work is licensed under the Creative Commons Attribution International License (CC BY). $\mathrm{http} / / /$ creativecommons.org/licenses/by/4.0/ 